\title{
Embajadores culturales: recepción y trascendencia del viaje de Gerardo Diego a Filipinas en el archipiélago asiático
}

\author{
Cultural Ambassadors: Reception and Importance \\ of Gerardo Diego's Journey to the Philippines \\ in the Asian Archipelago
}

\author{
Rocío Ortuño Casanova \\ Universiteit Antwerpen \\ rocio.ortuno@uantwerpen.be \\ ORCID iD: http://orcid.org/0000-0003-2636-8279
}

\section{RESUMEN}

Gerardo Diego llegó a Filipinas en misión cultural enviado por el gobierno de la II República en enero de 1935. Ese año el archipiélago aprobó una constitución que designaba provisionalmente el español y el inglés como lenguas oficiales, y pasaba de ser colonia estadounidense a «Estado libre asociado» como etapa previa a la independencia. En ese momento de ebullición política y gestación de influencias internacionales, el viaje de Diego adquiere una importancia que se refleja en la amplia cobertura por parte de la prensa local y en la extensa agenda de encuentro con autoridades que mantuvo el poeta durante los 47 días de estancia en el país. Este artículo realiza un recorrido por las posturas de la prensa filipina ante la llegada de Diego y una evaluación de las razones para la trascendencia del viaje, además de incluir un artículo suyo publicado en La Vanguardia de Manila, inédito en España.

Palabras Clave: Gerardo Diego; Generación del 27; literatura filipina en español; política cultural; relaciones hispanofilipinas.

\section{ABSTRACT}

Gerardo Diego arrived in the Philippines in January 1935 sent by the government of the Second Spanish Republic as cultural envoy. During that year the archipelago approved a Constitution which designed provisionally Spanish and English as official languages, and went from being an American colony to a commonwealth state, as preparatory stage for independence. In this moment of political crossroads and determination of international influences, Diego's journey acquired an unexpected importance, reflected in the coverage provided by local media and in the numerous meetings held with Philippine authorities during the 47 days that he stayed in the country. This paper reviews the positioning of Philippine press on Diego's visit and assesses the 
reasons for the transcendence of the voyage. It also includes a full article written by Diego for La Vanguardia from Manila, unpublished in Spain until now.

Key words: Gerardo Diego; Generation of 1927; Philippine Literature in Spanish; Cultural Politics; Relations between Spain and the Philippines.

En 2015 se cumplieron 80 años desde la embajada cultural que trajo a Gerardo Diego y al físico Julio Palacios al archipiélago filipino 37 años después de que España renunciara a la soberanía de las islas. El evento pasó prácticamente desapercibido en España y en la biografía del poeta: Antonio Gallego Morell (1956: 59), biógrafo de Diego, relata muy brevemente el episodio. Más tarde Elena Diego (1996: 32) vuelve a recordarlo en una nota en Ínsula. La peripecia se detalla de forma más extensa en el libro de Julio Palacios Filipinas orgullo de España, de 1935, en que el autor cuenta junto a su propia expedición el viaje de Diego. Las memorias de viaje del cántabro se publicaron por primera vez en 2007 con el título de Diario de a bordo, y constan de unas pocas notas del viaje en barco y varias cartas a su esposa, con una introducción de Jacques Issorel y de Anne Lacroix y algunos documentos escaneados del viaje. Más recientemente la Fundación Gerardo Diego ha colgado en su página web una serie de grabaciones que publicó en forma de $\mathrm{CD}$ en el número 5 de la colección Cuadernos Adrede, en las que Diego narra su biografía. Entre los diferentes episodios de la misma hay un epígrafe reservado para la visita a Filipinas ${ }^{1}$.

Entre sus poemas solo 12 sonetos de Alondra de verdad recuerdan los paisajes recorridos (Diego 2007: 15), siendo el que más explícitamente se refiere a Filipinas el titulado «Adiós», en que nombra algunas islas del archipiélago (y otras de Indonesia) en un verso que él describió en un artículo para Fotos como uno de los más musicales que había escrito: «Sábang, Pénang, Panay, Báli, Celébes» (Diego 1997: 315). Más tarde, en las décadas de los 40 y 50, el poeta escribiría algunos artículos en la prensa española que recordarían lo visto y vivido en Filipinas desde que llegaran Julio Palacios y él enviados por la Junta de Relaciones Internacionales de la II República al puerto de Manila el 4 de enero de 1935 a bordo del buque alemán Karnak, en una misión cultural que duraría 47 días (Diego 2007: 15). Parece ser que el viaje debería haberlo emprendido Dámaso Alonso (1988: 245), pero que por asuntos de salud declinó la oferta de la Junta de Relaciones Culturales. Así parece insinuarlo Diego cuando un reportero del Philippines Free Press sugiere que debía ser por su reputación y su alto nivel académico por lo que había sido seleccionado

${ }^{1}$ La grabación del fragmento sobre el viaje a Filipinas se encuentra en el siguiente enlace: <http://www.fundaciongerardodiego.com/gerar/autobiografia/autobio9> [ref. de: 21/08/2015]. 
para viajar a Filipinas, a lo que Diego respondió que en realidad Palacios y él eran los únicos que estaban disponibles en ese momento («Only Merit Counts» 1935: 42). Lo apresurado del viaje también lo desvela el propio poeta, tanto a posteriori en su biografía grabada ${ }^{2}$ como en el tiempo de los hechos en la propia Manila, donde repite a varios medios que se le informó del viaje tan solo 10 días antes de partir («Diego y Palacios elogian el progreso de Filipinas» 1935: 6).

No son, al contrario de lo que afirma Diego dramáticamente en el artículo «De Filipinas a Java, ¡Islas, más islas!», los «primeros enviados de España, treinta y siete años después de la pérdida de Filipinas, para que hablen de la patria lejana al puñado de españoles de la colonia» (Diego 1997: 310), aunque quizás sí los primeros que llegan a Zamboanga, que es del lugar del que habla posteriormente Diego en su artículo. Como recuerda María Lourdes Díaz-Trechuelo (2000: 677):

En ese tiempo, los lazos entre España y Filipinas no quedaron rotos, ni en el aspecto económico, [...], ni el cultural y afectivo; las islas recibieron la visita de ilustres personalidades españolas de las ciencias, las letras y las artes, como Salvador Rueda, en 1915, Vicente Blasco Ibáñez, que en su vuelta al mundo llegó a Manila en 1924. Bonilla San Martín estuvo allí el mismo año; Federico García Sánchiz dio sus primeras charlas en Manila el año 1925; al año siguiente estuvo Luis de Oteyza. González Gallarza y Lóriga volaron desde Madrid a Manila también en 1926. Fueron los primeros enviados oficiales de España después de la separación de las islas, y llevaron un mensaje del rey Alfonso XIII al pueblo filipino.

Alfonso XIII, según afirma Miguel Luque Talaván (2013: 80), pretendía devolver a España «su antiguo prestigio internacional» a través de la diplomacia, misión que decidió continuar el gobierno de la II República, como afirma Lorenzo Delgado (1994: 259), a partir de la reforma en 1931 de la Junta de Relaciones Internacionales, cuando los intelectuales reformistas procedentes de la Institución Libre de Enseñanza recuperan la gestión de las relaciones culturales con el extranjero. Por su parte, José Luis Neila (2002: 12) afirma que en cuestión de política exterior la II República intentó corregir los vicios de la monarquía que había mantenido aislada a España del panorama internacional, reavivando y «defendiendo una política internacional que resulte simpática y atraiga a los partidarios del progreso de todos los pueblos de la tierra» (Giménez Valdivieso en Neila 2002: 12) pero sin rupturismos, aprovechando la «persistencia de la tradición» (Neila 2002: 10) que en este caso se encarna en el impulso iniciado por los intelectuales españoles regeneracionistas de la generación del 14 (Neila 2002: 13-14), que efectivamente ya habían enviado gracias a la Junta para la Ampliación de Estudios estudiantes y profesores al extranje-

\footnotetext{
2 Véase la primera nota a pie de página.
} 
ro y habían promovido directa o indirectamente las embajadas culturales. El periódico Philippines Free Press, un semanario bilingüe en español e inglés perteneciente al escocés Robert McCulloch Dick, aprovecha un artículo sobre la presencia de Palacios y Diego en Filipinas para recordar las antiguas embajadas intelectuales similares en Filipinas que tuvieron lugar entre el fin de la guerra contra España y ese año de 1935, ampliando un poco la nómina de Díaz Trechuelo:

... el primero de dichos embajadores fue Don Salvador Rueda y Santos, que llegó a Filipinas en 1915, para cumplir la nobilísima misión que, por Real Orden le encomendara el Gobierno de nuestra antigua Metrópoli y que no tenía otro fin y mira, según él mismo anunció, que «el cambio de las más puras ideas artísticas y la desinteresada comunión del idioma».

Más tarde fueron desfilando por estas playas personalidades del calibre de D. Vicente Blasco Ibañez (1924); D. Adolfo Bonilla San Martin (1924); D. Federico García Sanchiz (1925); los aviadores Loriga y Gallarza (1925); D. Luis de Oteyza (1926); D. Miguel Fleta (1929); D. Camilo Barcia Trelles (1931); y, finalmente [...] los Sres. D. Rafael Marin Lázaro, D. Gerardo Diego y Julio Palacios, tres gloriosas lumbreras del saber y la ciencia hispanos ( $i_{i}$ Los embajadores se van!»1935: 53).

Sin embargo, la expedición cultural de 1935 tenía por la época en que se realizó una importancia especial, ya que en ese punto de los convulsos años 30 se vivía en Filipinas un momento crucial de definición de influencias y de definición de las que serían las lenguas oficiales, título por el que pugnaban el español, el inglés, el tagalo y el cebuano. Precisamente la escueta presencia que tiene la embajada cultural en la obra y la biografía de Diego contrasta con la amplísima cobertura que la visita tuvo en los periódicos filipinos en español a pesar de los importantes eventos que se estaban viviendo en el país y que coincidían a veces en portada con la agenda de los conferenciantes. Cabe destacar entre otros la asamblea que elaboró y aprobó la Constitución de la Mancomunidad filipina el 8 de febrero de 1935, mientras Gerardo Diego estaba en el país, los movimientos diplomáticos de Manuel L. Quezón que acabarían en la creación de la Mancomunidad filipina pocos días después de la partida de Gerardo Diego, y el ascenso en Europa del Nazismo, asunto que también aparece con frecuencia y revestido de cierta preocupación en la prensa filipina.

El periódico La Opinión publicó prácticamente todos los días la agenda del poeta, discursos sobre su figura, resúmenes de sus charlas y declaraciones sobre su persona. Del mismo modo, Philippines Free Press y La Vanguardia dieron también datos puntuales de los actos públicos a los que acudirían los españoles, e incluso en los periódicos exclusivamente escritos en inglés como The Tribune y El Comercio aparece la noticia. Según la prensa, los dos enviados de la Junta de Relaciones Internacionales cenaron a menudo con el presidente de la 
cámara y futuro presidente de la Mancomunidad filipina Manuel L. Quezón, con el cabeza de la oposición Sergio Osmeña, y con el presidente del Senado Claro M. Recto, lo que da idea de la trascendencia que se le dio a la ocasión en Filipinas, llegando a afirmar Diego en dos cartas a Germaine que llevaba una agenda de «Pequeño Presidente de República» (Diego 2007: 70, 73). Cabe preguntarse, pues, los motivos que llevan a conceder tanta relevancia a esta visita y que se hace ostensible tanto en la prensa como en la agenda de los visitantes.

\section{EL CONTEXTO}

En 1898, con el Tratado de París, España abandona la soberanía de Filipinas a manos de Estados Unidos que, contraviniendo o reinterpretando lo estipulado en el tratado decidió ignorar las cláusulas referentes a la independencia filipina pactada con el general Emilio Aguinaldo y, tras dos años más de guerra, iniciar una tutela que prometía una independencia posterior cuando las estructuras democráticas del estado estuvieran preparadas (Agoncillo 1990: 211-15).

Estados Unidos seguía por tanto en 1935 controlando Filipinas en un período de transición entre la pertenencia territorial a la gran potencia americana, y la pertenencia a una «Mancomunidad de estados libres asociados» (Commonwealth) a Estados Unidos. Este nuevo estatus, que además transformaría el nombre del país de «Islas Filipinas» a «Filipinas», comenzaría en noviembre de 1935. La transición apenas conllevó cambios reales efectivos aparte de la promesa relativamente firme de que en el plazo de diez años se otorgaría la independencia total al archipiélago (Lumbera 2002: 193-194). A finales de este mismo año de 1935, Manuel L. Quezón fue elegido presidente de la Mancomunidad filipina - supeditado al control del gobierno estadounidense- y dos años después promulgaría el acto por el que la lengua tagala pasaría a ser la lengua oficial del país ${ }^{3}$.

Florentino Rodao achaca a esta época, y en concreto a los años que median entre 1935 y 1946, la deshispanización de Filipinas, lo que según él se debería a la división de la comunidad hispana del archipiélago por la Guerra Civil española, la amenaza fascista, la reeducación durante la época de la Mancomunidad en preparación para la independencia del país durante los años 40, y la aniquilación de la población española remanente durante la II Guerra Mundial (Rodao 2014: 26-27). El que 1935 sea el punto de inflexión que determinaría el peso de la influencia española sobre el país nos hace pensar en la importancia real del momento que podría intentar aprovecharse desde España. De ahí

\footnotetext{
${ }^{3}$ Se puede ver el discurso en la página web de la Gaceta Oficial de Filipinas $<$ http:// www.officialgazette.gov.ph/1937/12/30/speech-of-president-quezon-announcing-thecreation-of-a-national-language-december-30-1937/> [ref. de: 21/7/17].
} 
las instrucciones que según Diego le dieron desde el gobierno cuando objetó su desconocimiento de la lengua inglesa para la misión: «Usted lo que tiene que hacer es nada más que defender el español, demostrar que allí la gente entiende el español, hablarles en español y hacer todo lo posible por la cultura española» (Diego 2008).

Más allá de la visita de los dos profesores se ven intentos de revitalizar las relaciones culturales bilaterales tanto desde Filipinas como desde España en varios flancos: en los meses en que Diego y Palacios están en Filipinas, Philippines Free Press anuncia la formación de una «Liga para la conservación y propagación del idioma castellano» en Filipinas y un concurso de declamación en español a finales de febrero en la Universidad de Filipinas «para dar mayor impulso al castellano» («Para dar un mayor impulso...»1935: 56), así como unas jornadas de charlas sobre relaciones hispanofilipinas que inaugura Adelina Gurrea el 9 de febrero de 1935 organizadas por la Asociación España Filipinas, creada pocos meses antes en Madrid («Al inaugurarse el ciclo...» 1935: 59). Asimismo, The Tribune del 29 de enero de 1935 muestra en una fotografía encabezada por el epígrafe «Spanish Savants Visit Association» ${ }^{4}$ a Diego y a Palacios visitando la recién creada "Asociación pro-idioma hispano», donde profesores voluntarios enseñaban español gratis a los filipinos que así lo deseaban. El resurgir de las relaciones hispanofilipinas tras la revolución independentista de 1896 se explica debido a cierto entusiasmo de los que se quedaron al pensar que la nueva potencia colonizadora sería más efectiva que la administración española y podría incluso facilitar y mejorar los negocios que los españoles y criollos tenían allí, como parece que en realidad ocurrió hasta la II Guerra Mundial (Rodao 2014: 64).

El ambiente receptivo coincidió con un nuevo ímpetu por parte de la República española en la comunicación con las antiguas colonias y la propagación del español. La recién creada Junta de Relaciones Culturales, tenía como prioridad en primer lugar la conservación de las señas identitarias de los emigrantes españoles — contribuyendo a las acciones de las asociaciones filipinas locales constituidas por la comunidad española desplazada - y en segundo lugar la intensificación de los vínculos con las excolonias «para recuperar la influencia española en el seno de la colectividad hispana» (Delgado 1994: 261) ${ }^{5}$. En este sentido, por ejemplo, la junta recopiló y envió siete bibliotecas de cultura superior a Argentina, Brasil, Chile, Colombia, Costa Rica, Perú y Filipinas (1994: 261), y por supuesto, envió conferenciantes al extranjero, como en el caso que nos ocupa.

4 «Los eruditos españoles visitan una asociación». Traducción propia.

${ }^{5}$ Dicha empresa, de cariz que se podría entender como neocolonialista, ha continuado hasta el siglo XXI, con el plan económico llamado «Triangulación Asia-España-América Latina». Véase Ortuño Casanova (2015). 


\section{LA CUESTIÓN DE LA LENGUA NACIONAL}

El 9 de febrero de 1935, mientras Gerardo Diego estaba en Filipinas, se publica en Philippines Free Press un artículo sobre la polémica de cuál ha de ser la lengua oficial de Filipinas (Gullas 1935: 41-42). En él se especifica que en una reunión en Cebú se acordó que el español sería lengua oficial hasta 1940 en que quedaría como oficial únicamente el inglés. Después pasa a especificar que hubo gran discusión sobre si el inglés o el español debía ser la lengua internacional de Filipinas, pero que de lo que no había duda era de que era necesario que una lengua nativa o una lengua basada en las lenguas nativas fuera la oficial del país. El debate, más allá de los periódicos, divide a la población, que, en un momento político clave para Filipinas en que se están asentando las bases de su funcionamiento cuando se independice diez años después, se ve en la situación de tener que elegir entre áreas de influencia.

La cuestión no es solo lingüística ni baladí; como bien afirma la crítica francesa Pascale Casanova (2001: 159), el peso del prestigio de las lenguas y la canonización de la literatura en una lengua colonial determinada en las sociedades postcoloniales en que el dominio literario está intrínsecamente relacionado con el dominio político, determina identidades y afinidades políticas a través de la lengua y la literatura, y gesta «áreas lingüísticas (o lingüístico-culturales) como una especie de expansión de los espacios literarios nacionales europeos»».

Concretamente sobre la pugna para ser la «lengua literaria» de Filipinas han corrido ríos de tinta. Resil Mojares (1998: 194) afirma que el cambio de dominio colonial en Filipinas creó la simpatía de los progresistas hacia lo estadounidense - y por tanto hacia el inglés - y la oposición de un grupo conservador que se veía depositario de las virtudes católicas y sociales tradicionales de la anterior colonia española. Wystan de la Peña (2000) por su parte mantiene otra de las opiniones sobre el tema que apunta al hecho de que en el momento que llegan los americanos y después de 333 años de ocupación, la lengua española es ya parte de la identidad filipina, y por tanto los ilustrados la utilizan como lengua de resistencia anticolonial ante el nuevo invasor. Lo cierto es que aunque la nueva potencia colonial es Estados Unidos, el prestigio cultural entre las élites dominantes del país sigue estando vinculado al español. Nora T. Jolipa (1996: 24 y 30) hace un recuento de las reacciones antiamericanas de múltiples ilustres hombres de letras filipinos en su artículo «Lost Paradise: American Colonialism and the Filipino Writer in Spanish». La empresa, como los mismos escritores en lengua española acertaron a imaginar, era complicada al tratarse, como afirma Casanova (2001: 159), no solo de una lengua, sino de una polarización política, un enfrentamiento de potencias por mantener un área de influencia, enfrentamiento que además ya había tenido lugar en otros territorios colonizados sucesivamente por España y Estados Unidos como era Puerto Rico (Morris 1995: 28-30, 162-163). 
Estados Unidos había emprendido desde el día de su llegada a Filipinas una sistemática reeducación de la población trayendo ejércitos de profesores y enseñando inglés hasta en los rincones más recónditos del archipiélago, como relata Diego lleno de preocupación en un artículo de 1946 en $A B C$ :

Los Estados Unidos desde el primer día usaron de todo su poderío y su tenacidad para imponer con celeridad maravillosa la lengua inglesa. El castellano no fue proscrito ni prohibido, pero sí relegado a la categoría de lengua extranjera, en la cual no se podía enseñar. (...) El resultado de esa estratégica campaña ha sido la imposición del inglés como lengua incomparablemente más difundida hoy que la nuestra, sobre todo en las generaciones jóvenes (Diego 1997: 613).

Sin embargo, según Florentino Rodao (2012: 463-468), en la primera mitad del siglo XX, a pesar de que el número de periódicos en inglés es más alto que el de periódicos en español, los periódicos en español estaban más extendidos por el país, tenían más tirada y se publicaban con más regularidad, lo que nos proporciona cierta idea sobre la influencia cultural que mantiene la lengua española. Además, los hispanohablantes forman parte de las cúpulas políticas del país, incluyendo a Claro Recto, escritor en castellano con obras teatrales que fueron publicadas y representadas, como Solo entre las sombras. Recto era desde 1934 presidente de la mayoría del senado, y fue parte de la comisión constitutiva de la nueva «Mancomunidad» filipina. Afirma Eugenio Matibag (2013: 179) sobre el papel del español en la época y concretamente sobre la intención de Recto al escribir en español:

As manifest in Philippine hispanophone literature and culture in general, the Castilian language, despite its status as a minority language, provided a counterweight to the hegemonic imposition of English, which had swiftly become the language of business and bureaucracy during the Occupation. Philippine poetry, narratives and plays that were written in Spanish offered a version of a patrimony, a national identity that was to be built on a Hispanic foundation. Recto's dramatic productions thus contributed to the vindication of Hispanicity which also endorsing the prerogative of his Castilian-speaking class for setting the national agenda ${ }^{6}$.

${ }^{6}$ «Como queda manifiesto en la literatura hispanófona y la cultura en general, el lenguaje castellano, a pesar de su estatus de lengua minoritaria, proporcionó un contrapeso a la imposición hegemónica del inglés, que se había convertido rápidamente en la lengua de los negocios y la burocracia durante la ocupación. La poesía filipina, la narrativa y las obras teatrales que fueron escritas en español ofrecieron una versión de un patrimonio, una identidad nacional, que estaba por construirse sobre cimientos hispánicos. Las producciones dramáticas de Recto, por lo tanto, contribuyeron a la reivindicación de la hispanidad que también respaldaba la prerrogativa de su clase castellanoparlante de establecer la agenda nacional» (traducción propia). 
Por otro lado, la impresión de Julio Palacios (1935: 85) es que en el momento que ellos visitan Luzón, «se ha despertado entre los filipinos una corriente sentimental de cariño hacia España» con lo que hablan más español del que se ha hablado nunca en Filipinas. Estos factores eran atisbos de esperanza que hacían pensar que todavía se podía inclinar la balanza a favor del español, lo que convertía la llegada de los dos emisarios culturales en un esperado impulso para los hispanófilos en Filipinas.

\section{COBERTURA EN LOS PERIÓDICOS}

En estas circunstancias se encuentra el archipiélago cuando desembarcan del Karnak Gerardo Diego y Julio Palacios. En España ambos eran personalidades de reconocido prestigio en su campo. En el caso de Gerardo Diego, como poeta perteneciente a la brillante generación del 27, en 1935 había publicado ya 8 poemarios y la antología Poesía española 1915-1931, que daba a conocer a la pléyade de literatos que tuviera su apogeo durante la II República española, y sin ser aún académico, sí que tenía experiencia en embajadas culturales de alguna manera similares, ya que entre julio y noviembre de 1928 había viajado a Argentina y Uruguay, donde dio varias conferencias sobre la poesía contemporánea española.

Aunque es dudoso que el desglose de sus méritos se conociera en Filipinas, los periódicos en inglés y en español anunciaron su llegada a bombo y platillo. Los adjetivos «eminent» (en The Tribune), e «ilustre» y «distinguido» ( $L a$ Vanguardia y Philippines Free Press) siempre preceden al nombre de Diego y Palacios en los diferentes artículos, aunque en ocasiones el motivo de su visita y sus títulos académicos se confundieran: el semanario Philippines Free Press, por ejemplo, anuncia con una semana de retraso la llegada de los «embajadores culturales» (el 2 de febrero también diría que Diego y Palacios llegaron en diciembre en la página 41) afirmando que llegan «deseosos de establecer en Manila una sección de la academia de ciencias» («Los embajadores hispanos» 1935: 56), objetivo que no solo no se ve realizado, sino que no aparece en las declaraciones de los propios enviados. El mismo semanario, le atribuye a Diego un doctorado por la universidad de Salamanca que no nos consta («Spain’s cultural envoys» 1935: 42) 7 .

${ }^{7}$ En posteriores números sí que se preocupan de averiguar más sobre las publicaciones y premios de Diego: en un artículo del 2 de febrero, el periodista le pregunta directamente a Diego por sus méritos («Only Merit Counts» 1935: 42) y en el mismo número glosan algunas de las publicaciones de Diego: «"Poesía española" an anthology of modern Spanish poetry; "Versos Humanos", which obtained the first prize in a national literary contest in Spain in 1924-1925; and "Viacrucis"» («Spain's Cultural Envoys» 1935: 42), e incluso publican uno de sus poemas, «Amor profano y amor divino», que leyó en una cena en el 
Sin embargo, el desconocimiento de los méritos exactos de Diego y del objetivo específico de su visita no quita para que el viaje sea todo un acontecimiento en el país, lo que nos devuelve al valor simbólico de la presencia de los dos profesores. The Tribune publica justo el día después de su llegada, el 5 de enero, un artículo llamado «Spanish Educators Arrive, Will Lecture» con una foto de Diego, Palacios, el cónsul Miguel Espinós y la comitiva de recibimiento que incluía al cónsul Miguel Espinós, encabezado con la interpretación que se le da a la visita desde el periódico: «Indicative of the great interest that the Spanish Republic has taken in the Philippine-Spanish cultural relations, two eminent Spanish educators and lecturers (...) arrived in Manila» («Spanish Educators...» 1935: 3$)^{8}$. La justificación continúa en el siguiente párrafo del artículo:

The two Spanish educators have been sent here by the Spanish Filipino committee of the department of state for the purpose of fostering pro-Spanish culture among the Filipinos, promoting and advancing the influence of Iberian learning in science and literature, reviving the old Philippine love for Spanish traditions, and furthering the relationship among the intelligensia of the two nations («Spanish Educators...» 1935: 3) .

El periódico, nacido en 1925 y cuyo dueño era Don Alejandro Roces, dueño también del diario en español La Vanguardia, se enorgullecía en su eslogan de su independencia ideológica, «Independent Filipino Daily» se hacía llamar, y era comprado diariamente por una media de 35000 lectores (Trota 1990: 45). En la noticia que nos ocupa parece asomar una sombra de sospecha sobre las intenciones de la repentina visita de las dos autoridades intelectuales mandadas por España. La mención del pasado, aunque sea de forma sutil, sugiere cierto intento de neocolonialismo cultural, y la resurrección («reviving») de nostalgias añejas. Por otra parte, el hablar de cultura «pro-española» parece indicar la división social en dos bandos que pugnan por la «influencia» que también se menciona en el texto. Dicho recelo queda también de trasfondo entre las múltiples referencias a la «conquista», «reconquista»y «colonización» que apare-

casino español el 24 de enero y en el Centro Escolar de Señoritas («Columna lírica» 1935: 53; «Diego habla de la mujer...» 1935: 3).

8 «Prueba del gran interés que la República española tiene en las relaciones culturales entre España y Filipinas, dos eminentes educadores y profesores españoles han llegado a Manila». Traducción propia.

9 «Los dos educadores españoles han sido enviados por el comité hispanofilipino del departamento de estado con el objetivo de fomentar una cultura pro-española entre los filipinos, promoviendo y potenciando la influencia del aprendizaje ibérico en cuestión de ciencia y literatura, reviviendo el viejo amor filipino por las tradiciones españolas e impulsando la relación entre la intelectualidad de las dos naciones» (traducción propia). 
cen en los diferentes diarios. Philippines Free Press utiliza estos símiles en su panegírico a los enviados del 26 de enero de 1935:

Desde hace muchos años, de tiempo en tiempo nuestra vieja Madre España viene enviándonos espléndidos embajadores espirituales con el fin de llevar a cabo una cruzada de paz y de cultura, para afirmar y ampliar la obra de reconquista emprendida por hombres de buena voluntad y cifrada toda ella en el amor más puro y desinteresado. («iLos embajadores se van!» 1935: 52).

Las menciones a la «cruzada de paz» y la «reconquista» remiten a viejas relaciones con España en tiempos de la colonia. Una relación desequilibrada de dependencia que pretende renovarse y corregirse borrando precisamente las reminiscencias del pasado que se traen a colación en The Tribune y Philippine Free Press. Este mismo mensaje de renovación aparece en el editorial que explica una caricatura de Palacios, Diego y Marín aparecido en portada en el mismo Philippines Free Press del 26 de enero: "Sin la cruz de Urdaneta ni la espada de Legaspi [sic], ellos han hecho conquistas en Filipinas por la magia de su oratoria y la profundidad de su erudición» («Cultural Emissaries» 1935: 1). Los vínculos culturales prevalecen en este establecimiento de nuevas relaciones entre ambos países en vías de renovación: España con su reciente República intenta mostrarse a través de las charlas de Gerardo Diego y Julio Palacios como un país progresista, redimido, un país de artes, música, literatura y avances científicos, manteniendo lo mejor del pasado y mirando al futuro. Las conferencias de Gerardo Diego versarán precisamente sobre literatura, música y pintura, ofreciendo una imagen de España como país de artistas, muy en línea con el impulso cultural de la República y paralelo a los esfuerzos que se hacían en España por medio de las misiones pedagógicas. La lista de conferencias ofrecidas en la Universidad de Filipinas entre el 9 y el 18 de enero de 1935 así lo evidencian: «Literatura contemporánea española» el 9 de enero, «Pintura española hasta el siglo XIX» el 10 de enero, «La poesía contemporánea española» el 11 de enero, «Música española hasta el siglo XIX» el 14 de enero, «Lengua y cultura española» el 15 de enero y «Sobre Isaac Albéniz como compositor» el 18 de enero. El 17 y el 19 de enero habla en Santo Tomás sobre Enrique Granados y Manuel de Falla, y toca algunas piezas de ambos. De hecho la diversidad de temas y lo polifacético del cántabro, es comentado con cierta sorna en Philippines Free Press («Spain’s Cultural Envoys» 1935: 42).

Por su parte, Julio Palacios, según la carta que el cónsul Miguel Espinós mandó al Ministerio de Estado, impartió cursos sobre los átomos, la expansión del universo, el concepto de entropía, la plasticidad de los sólidos, los nuevos elementos radioactivos, la física nuclear y la mecánica ondulatoria, sobre tiempo y espacio, sobre la nueva astronomía y sobre luz y sonido (Diego 2007: 90-91). Un calculado equilibrio de temas que muestran precisamente el progreso de España en materia científica gracias a los esfuerzos que desde la prime- 
ra década del siglo XX se venían haciendo para europeizar España y ponerla a la vanguardia de la investigación (Gimeno Perelló 2011). Los periódicos filipinos así lo entienden y recogen, aprovechando para promocionar lo español en una nueva luz, divergente de la imagen de oscuridad, fanatismo religioso, tradición y superstición que existía desde el siglo XIX en Filipinas (Kramer 2006: 51-54). Gerardo Diego llega a decirlo abiertamente como conclusión de una de sus conferencias en la Universidad de Filipinas, tal y como recoge el periódico La Opinión el 16 de enero de 1935 citando palabras de Diego: «España es una nación liberal y moderna! España es un país rejuvenecido!».

Sin embargo, a menudo en los medios, y en especial en La Opinión, más que el rejuvenecimiento de la antigua metrópoli interesaba la opinión que esta tenía de lo filipino, y mostrar al mundo que Filipinas era culturalmente valioso en sí mismo y no solo por su herencia hispana para los enviados españoles. Así pues, a lo largo de la estancia de Diego y Palacios en Manila, van publicando puntualmente artículos en los que sobre todo Diego menciona y alaba algo filipino. El 9 de enero de 1935, apenas 5 días después de la llegada a Manila, el titular del artículo dedicado a los conferenciantes es «Diego y Palacios elogian el progreso de Filipinas» (1935: 6), reproduciendo parte de las palabras pronunciadas por los conferenciantes en un discurso de brindis en el ágape ofrecido en su honor por el empresario Joaquin M. Elizalde en Manila Hotel. En concreto el poeta «admiró mucho el estilo de expresión de los elementos del habla española en las islas y reiteró su confianza en que el castellano seguirá desarrollándose aquí» (1935: 6). El 11 de enero el mismo periódico se enorgullece de la mención de dos pintores filipinos en la charla de Gerardo Diego sobre arte en la Universidad de Filipinas. El titular reza: «Luna y Resurrección Hidalgo mencionados por el Profesor G. Diego en su conferencia». Son algunos más los pintores filipinos mencionados (Villanueva y Zaragoza, según desgrana posteriormente el artículo), pero en la conferencia no se dijo de ellos más que «fueron los pintores filipinos más destacados de la era pasada» («Luna y Resurrección Hidalgo...» 1935: 4). Desde luego el peso de la conferencia no se centró en estos artistas sino, como era de esperar a partir del título de la misma, en la pintura española hasta el siglo XIX. La importancia de la mención de los filipinos estriba más en la autoafirmación cultural por parte del periódico, que en la relevancia que realmente les diera Diego, sin embargo en la época de construcción nacional en la que se encuentran, es revelador que más que lo español interese escuchar el reconocimiento a lo filipino en boca de un extranjero.

Parece que el cántabro se percatara de tales querencias del público del lugar, con lo que continuó haciendo mención a ilustres filipinos en sus charlas. Así el titular de La Opinión del artículo referido a la conferencia de Diego, parece citarlo al rezar «Enorgulleceros [sic] de Rizal-Diego». Aunque su charla trataba sobre la poesía española contemporánea, Diego afirmó «Filipinas debe enorgullecerse de haber tenido un gran poeta en la persona del Dr. José Rizal» 
(«Enorgulleceros de Rizal»1935: 2). La mención de Rizal, además de hacer las delicias de los filipinos en cuanto a la reafirmación cultural ya mencionada, tiene mayor simbolismo al establecer cierta nueva hoja de ruta en las relaciones hispanofilipinas. El libro de José Rizal El filibusterismo fue prohibido por la administración española de Filipinas tras su publicación (Álvarez Tardío 2012: 130). Rizal fue condenado primero al destierro a Mindanao y luego fusilado en 1896 por las tropas españolas. La mención al alto nivel literario de Rizal podría ser interpretada como una ruptura implícita con el régimen que lo fusiló, tendiendo lazos de reconocimiento a la nación filipina y de admisión de los errores anteriores cometidos en el trato hacia la misma.

Tanto el Philippines Free Press como La Vanguardia acaban sumándose a la publicación de los halagos de los españoles a los filipinos al señalar la grata impresión que causaron en Diego y en Palacios las dos obras en español representadas en su honor por el Círculo escénico, una asociación de teatro amateur, 4-3-4-3-4 de Francisco Liongson, y Los desorientados de Antonio M. Abad. El 13 de febrero publica La Vanguardia un artículo titulado «La función del Círculo escénico fue una grata revelación para los eminentes catedráticos españoles», en la que se afirma que «los catedráticos no pudieron contener su asombro y regocijo ante la brillante preparación escénica y la dirección correcta y clara de los actores aficionados que intervinieron en la representación» («La función del Círculo...»1935: 5). Por su parte, el artículo de Philippines Free Press que sale el 23 de febrero es bastante más sobrio, al limitarse a citar lo dicho por Diego acerca de las obras: «He tenido el honor de asistir al estreno de "4-3-4-3-4" del Sr. Liongson y he saboreado un admirable cuadro de costumbres filipinas dialogado con ingenio en un castellano ágil y correcto» («Palacios y Diego comentan sobre el teatro filipino»1935: 53), palabras de una mesura mucho más cercana a la falta de entusiasmo con la que luego en privado Diego escribe acerca de la obra en carta a Germaine del 19 de febrero: «El día 12 tuvimos la función del Círculo Escénico en honor nuestro: esa ha sido la función de la mala pata. Nos ha desbaratado los planes de excursiones y ha sido nuestra pesadilla. En efecto, a última hora todo salió perfecto, pero al llegar a casa noté la falta de uno de los gemelos de oro de papá y por más que hemos preguntado no ha aparecido» (Diego 2007: 77).

Finalmente, sin embargo, la impresión general acerca del viaje sí que coincide tanto en las cartas como en los artículos posteriores en que fue excelente. Antes de que marcharan, La Vanguardia de Manila le pide a Diego una nota de despedida del país que publica en el número del día 22 de febrero de 1935 en portada. En ella, el poeta evalúa su experiencia filipina. El artículo no ha sido nunca publicado en España - y lo he encontrado en Filipinas en versión microfilmada en una sola biblioteca- Reproduzco, pues el artículo completo dado su valor para este estudio así como complemento de la magnífica recopilación de las prosas del cántabro que realizó en su día el profesor Francisco Javier Díaz de Revenga para la publicación de las monumentales obras com- 
pletas de Gerardo Diego, donde sí que aparecen otros artículos del poeta sobre Filipinas publicados ya de vuelta en España (Diego 1997), y complemento también del más reciente volumen Diario de a bordo en que se publican las cartas y anotaciones en el diario que llevó Diego en su viaje a Filipinas.

Nada más hermoso que la mujer filipina. -G. Diego

En vísperas, ay! [sic] de viaje, LA VANGUARDIA me solicita una impresión sobre Filipinas. Entre baúles y maletas abiertas, con el aturdimiento propio de mi marcha en tales circunstancias, escribo sobre el respaldo de una caja esta apresurada cuartilla. Filipinas es una increíble maravilla. Un prodigio en primer lugar de bellísima varia naturaleza. Me quedo con nostalgia de lo mucho que me falta por conocer, pero estoy contento de haber visto Manila, la más airosa y culta ciudad del Oriente, llena para mí de emociones y recuerdos españoles, y sus provincias limítrofes.

Encantado de mi viaje a Iloilo, Cebu, Negros y Zamboanga, donde he admirado paisajes para mí completamente nuevos, y he aprendido muchísimas cosas. Maravillado, finalmente, de Baguio y de la Provincia Montañosa, donde los recuerdos de los paisajes de mi tierra natal se entrelazaban con las sorpresas crecientes de tantas perspectivas insólitas.

¿Hay algo en el mundo más hermoso que una puesta de sol en la Bahía de Manila, que los bosques de cocoteros de Zamboanga, que las terrazas de Banaue? Iba a decir que no, pero... sí. Hay algo más hermoso: la belleza de la mujer filipina.

La vida intelectual y universitaria de Manila me ha producido una magnífica impresión. He encontrado en Manila como en provincias públicos muy cultos y distinguidos que sabían captar con pronta agudeza los conceptos, a veces necesariamente sutiles, de mis disertaciones literarias y artísticas. Esas juventudes universitarias son orgullo de Filipinas y la mejor prenda de su inmediata y gloriosa madurez política e intelectual.

Como español, he sentido muchos momentos de emoción, conviviendo con mis compatriotas, comprobando que la colonia española, presidida siempre por nuestra dignísima representación consular, que con tanto fervor trabaja aquí por España, es un modelo de laboriosidad, espíritu emprendedor y compenetración fraternal con el país. Aún le quedan a España siglos de arraigo espiritual y económico en Filipinas. Estoy seguro de ello.

Para terminar, gracias a todos. Desde las más altas autoridades, hasta los más humildes servidores, todos me han colmado, según su rango, de atenciones, agasajos y cortesías. Gracias como español y como

\section{GERARDO DIEGO.}

Sin duda la misiva atiende a las expectativas de La Vanguardia al solicitar dicha nota. La alabanza a la inteligencia de los filipinos, a la mujer filipina —en otros artículos se celebran los piropos que tanto Palacios como Diego les dedican («Diego habla de la mujer como suprema inspiradora» 1935: 2 y «Only Merit Counts» 1935: 42) - la naturaleza del país y a la comunidad hispanohablante constituyen el reconocimiento por parte de una alta figura del hispanis- 
mo representante de la acción cultural de España a una antigua nación subyugada por el imperio y humillada por la acción cultural decimonónica que promovió la muy criticada exposición de Filipinas en el Palacio de Cristal en $1887^{10}$, en escritos de colonos ${ }^{11}$, y por la política colonial que no permitió que Filipinas tuviera representación en el congreso.

\section{LOS DISCURSOS DE AUTORIDADES Y LA RELEVANCIA POLÍTICA DE LA EMBAJADA CULTURAL}

Pero el simbolismo de la embajada cultural no quedó solo reducido al ámbito de los periódicos. Los discursos, artículos y poemas de personajes relevantes que se escriben acerca de la visita de Diego y Palacios inciden más precisamente en la situación política filipina y la necesidad de replanteamiento de las relaciones con España, esta vez de tú a tú, que en las especialidades de los académicos y el progreso español.

Sorprendido por la grata acogida que tuvo la visita de los profesores en la University of the Philippines (UP), Julio Palacios reproduce parte del discurso de presentación en perfecto español que ofrece el rector de la universidad Jorge Bocobo para presentar a Gerardo Diego antes de su conferencia del día 10 de enero de 1935 (Palacios 1935: 54). El discurso aparece completo en La Opinión del 11 de enero («Luna y Resurrección Hidalgo...» 1935: 4). Bocobo destaca precisamente la importancia de la presencia de los embajadores culturales en el «momento de reconstrucción nacional» que vive Filipinas. Continúa expresando su deseo de que la identidad hispana forme parte de la nueva nación filipina:

Es que esa reconstrucción del edificio nacional ha de ser integral y arquitecto ciego, ignorante y temerario debe ser aquel que nos aconseje despreciar los cimientos que aquí encontró Dewey cuando en 1898 declaró que los filipinos ya éramos capaces para el gobierno propio. Pues que: ¿acaso hubiese sido posible efectuar aquí un progreso tan admirable en el breve espacio de tres décadas a no haber sido por la obra de civilización occidental de España por más de tres centurias? Y ahora que América por fin nos reconoce el derecho de edificar nuestro

${ }^{10}$ El Palacio de Cristal del Parque del Retiro de Madrid se construyó para albergar en 1887 una exposición etnológica sobre Filipinas, que albergó minerales plantas filipinas y una tribu de igorrotes, dando una imagen de tierra salvaje e incivilizada muy contraria a las aspiraciones de los filipinos ilustrados - muchos de los cuales habitaban en España- que pugnaban por la representación de Filipinas en las cortes españolas (Sánchez Gómez 2002 y Kramer 2006: 35-37).

${ }^{11}$ Pablo Feced, apodado Quioquiap era uno quizás de los articulistas más denigrantes con los filipinos. Véase Quioquiap (1888). Filipinas: esbozos y pinceladas. Manila: estab. Tipográfico de Ramírez y compañía, disponible en: http://www.cervantesvirtual.com/portales/literatura_filipina_en_espanol/obra/filipinas-esbozos-y-pincelasa/ [ref. de: 22/08/2015]. 
propio hogar social y político [...] el pueblo debe impelernos a recoger las piedras y los fundamentos un tanto olvidados que España ha dejado en estas islas [...] los valores espirituales, el arte y la literatura («Luna y Resurrección Hidalgo...»» 1935: 4).

Estas palabras hacen patente los acelerados procesos a los que se sometía Filipinas en la época y la pugna de influencias. Bocobo (1935: 4) aún es más explícito al afirmar que la cultura hispana ha de ser crucial para que «la orientación de la vida nacional no se pierda en el camino del grosero materialismo» traído por Estados Unidos. Lo hispano como lo idealista y humanístico del país es defendido por los intelectuales de la época, a menudo representándolo con la imagen Don Quijote, mientras que el otro colono, más cercano a valores que en el contexto latinoamericano se denominarían como Barbarie tiende a representarse en la época en la figura de Sancho Panza en múltiples textos y poemas ${ }^{12}$. Precisamente a esta dicotomía de valores se refiere Bocobo para enfatizar la importancia de que los filipinos escuchen y recuerden la cultura española que es parte de su civilización.

El futuro presidente de la Mancomunidad Manuel L. Quezón también alaba, según Palacios, la colonización española de Filipinas en comparación con la ocupación holandesa en Indonesia y reconoce las aportaciones españolas inestimables de la cultura hispana y la religión católica (Palacios 1935: 62). Quezón omite la lengua española, tema espinoso durante su mandato: tras varias declaraciones contradictorias respecto a la lengua nacional realizadas a lo largo de los años, en 1940, en una conferencia ofrecida por el primer aniversario del Philippine Writers' League, el ya presidente de la Mancomunidad se reafirma en la decisión de que el tagalo sea lengua oficial del país, pero destaca la importancia de salvaguardar la herencia cultural y lingüística española, aunque se adivinan objetivos mucho más concretos y terrenales que los que sugería Bocobo:

It is important to preserve the Spanish language too. It is the interest of the Philippines to have some cultural connection with South America. I am not going to elaborate any further on this point tonight, but I want you to know and to understand that it is of great importance to us that the people of Latin America as well as of Spain look upon us as a people possessing the same Latin culture ${ }^{13}$ (Quezón en Arguilla, Nedruda y Agoncillo 1940: 30).

12 Sobre este tema se puede consultar el artículo de Ortuño Casanova (2014: especialmente 163-164). En ellas se citan, entre otros, los poemas de Bernabé «La muerte de Don Quijote» y de Fernando María Guerrero «Hispania», que ilustran la idea propuesta.

13 «Es importante conservar la lengua española también. A Filipinas le interesa tener alguna conexión cultural con Sudamérica. No voy a extenderme más sobre esto esta noche, pero quiero que sepáis y comprendáis que es de gran importancia para nosotros que la gente de América Latina y la de España nos consideren gentes con una cultura latina común». Traducción propia. 
Los motivos que decide no revelar se adivinan económicos, aunque tenga en cuenta los cimientos culturales comunes de las naciones latinas al incluir entre ellas a Filipinas. El senador Recto, por su parte, en el banquete que ofreció en honor de los visitantes el día 19 de enero («Recto Entertains for Spanish Savants» 1935: 32) sí que reclama como herencia dejada al pueblo filipino la lengua española, antes que ningún otro aspecto cultural:

(Han quedado) las huellas de ciertas modalidades de su genio y cultura, destacándose sobre todas su inmortal idioma, ese Paladión de los pueblos de tradición hispánica, archivo inviolable del pensamiento, arca santa donde guardan su herencia espiritual las «ínclitas razas ubérrimas» cantadas por Darío y tesoro común de emociones divinas, que logramos salvar incólumes, sobre todas las iras rencores y malquerencias del gran desastre colonial (Palacios 1935: 63).

Recto, más inclinando hacia la lengua española que el anglófilo Quezón contrapone esta herencia a los desmanes de la antigua autoridad colonial, la que genera «rencores y malquerencias» que se intentan soliviantar con la visita cultural de Diego y de Palacios. Es quizás el que más explícitamente menciona aquellas reticencias apenas insinuadas en algunos periódicos de los que hablábamos más arriba. Es innegable que el trabajo de restablecimiento de vínculos culturales 37 años después de la descolonización de un país para la que fue necesaria una guerra es arduo y debe borrar las susceptibilidades naturales mediante, como se ha venido explicando, la presentación de una nueva España capaz de ofrecer una nueva relación cultural en términos de igualdad. Así entiende Recto la labor de los embajadores y así lo expresa:
Ningún país en el mundo (...) ha dado hasta ahora en la flor de mantener comer- cio espiritual y afectivo con sus antiguos dominios, fuera del país hispano, que ha adoptado como norma de su política exterior la renovación de antiguos víncu- los de afecto con los pueblos donde un tiempo ondeara su enseña, acabando así de rescatar plenamente culpas o errores del pasado mediante una labor continua- da de civilización y cultura (Palacios 1935: 63).

La idea de redención está presente pero también la de comercio, como se vislumbraba en el discurso posterior de Quezón. En cualquier caso, las tres personalidades filipinas intentan adivinar razones ocultas detrás de la embajada cultural sin dejar de celebrarla y reconociendo la herencia recibida de la colonia española, dejándose llevar pues por esta iniciativa regeneradora de nuevos lazos entre dos nuevas naciones, conscientes de que comparten, eso sí, un pasado común que se deberá aprovechar y a veces redimir.

Finalizo las elucubraciones sobre los lazos de Filipinas y España que realizan estas insignes personalidades de la época al caso de la visita oficial de Gerardo Diego con el poema que le dedica Jesús Balmori, poeta admirado por Diego y al que dedica la parte titulada «Un poeta filipino» de sus «Estampas filipinas», un artículo relativamente extenso publicado en Revista de Indias en 1946 en el 
que describe diferentes aspectos de sus impresiones sobre el país (Diego 1946: 594-596). Diego, que asistió a la representación de la obra de Balmori Flor del Carmelo en el Opera House de Manila, afirma sobre el literato que

... adopta los ritmos desmayados o enérgicos, las valientes metáforas y la melancólica sentimentalidad sensual de la mejor poesía de la década inaugural del siglo. [...] Desde el trópico, la sangre late con una urgencia que no tolera astucias, celebridades o asepsias de orden y paciencia cristalográficas. El poeta se encuentra muy a gusto con imágenes, por otra parte tan legítimas y poéticas (Diego 1946: 594-595).

Propone como ejemplo de lo dicho el poema de Balmori «Al volcán de Taal». Propongo aquí en su lugar el soneto que publica Excelsior dedicado al cántabro en su número del 30 de abril de 1935, también fruto de ese modernismo rubeniano perenne que en que quedó detenida la literatura filipina en español hasta sus últimos estertores en los años 80 (véase, por ejemplo, el poemario Capullos de Nilda Guerrero), mientras la literatura nacional seguía su curso en inglés y en otras lenguas autóctonas:

Poeta de la España: en la azul telaraña

De tu verbo tendido por los indios nipales,

Romántica y nostálgica y cautiva está España!

Está España diciendo sus bellos madrigales!

Sé con ella, en la indígena y rústica cabaña,

Bajo el tendal sonoro de los cañaverales,

Templo de amor ardiente que el mar de Oriente baña

Y con sus ramos de oro besan los arrozales!

Mi musa, que se envuelve en la ves e encantada

Que una noche de luna, sobre la mar callada

Deslumbró tu mirada como un sueño de seda,

Arranca a su cintura su tapis de colores

Y lo tiende amorosa como un velo de flores,

Sobre el nido de cañas y nipas que te hospeda! (Balmori 1935).

A modo de conclusión recapitulemos diciendo que la visita de Gerardo Diego y la ajetreada agenda de encuentro con autoridades y charlas sobre la cultura española parecen suponer en la Filipinas de la época un último intento de inclinar la balanza hacia lo hispano a la hora de configurar una identidad nacional por parte de las élites hispanohablantes, a la vez que una declaración de intenciones en cuanto a la nueva forma de relación de la antigua metrópoli con la antigua colonia en situación de igualdad, siguiendo las directrices marcadas por la política exterior de la II República, que se proponía como ejemplo de país modernizado, laico y liberal. Los esfuerzos no tuvieron el fruto espe- 
rado: a la visita de Diego no siguieron las visitas esperadas y predichas en el discurso de Recto (Palacios 1935: 64) entre otras causas por las consabidas circunstancias históricas: un año y medio después de la visita de Diego se desencadenó en España la Guerra Civil, y al término de esta Filipinas se vio inmersa en la II Guerra Mundial e invadida por Japón, cuyas fuerzas destruirían Manila ensañándose especialmente con los barrios de más densidad hispanohablante: Intramuros y Ermita. Gerardo Diego escribió con posterioridad algunos artículos en los que demandaba con cierta urgencia la creación de un centro cultural español en la capital filipina para mantener y avivar la lengua española (Diego 1997: 600-601, 610-611). Sus aspiraciones se verían cumplidas en parte con la inauguración del Centro cultural de la Embajada de España en Manila, que posteriormente se convertiría en el Instituto Cervantes de Manila, lugar en el que se celebró en noviembre de 2015 precisamente una exposición sobre la visita de Gerardo Diego a Filipinas.

\section{Fuentes}

«Al inaugurarse el ciclo...» (1935). Philippines Free Press. 9 de febrero, p. 59.

Balmori, Jesús (1935). «Un canto en el camino», Excelsior. 30 de abril.

«Columna lírica» (1935). Philippines Free Press. 2 de febrero, p. 53.

«Cultural Emissaries/ Emisarios culturales» (1935). Philippines Free Press. 26 de enero, p. 1.

«Diego y Palacios elogian el progreso de Filipinas» (1935). La Opinión. 8 de enero, p. 6.

«Diego habla de la mujer como suprema inspiradora» (1935). La Opinión. 26 de enero, pp. 2-3.

«Enorgulleceros de Rizal» (1935). La Opinión. 12 de enero, p. 1.

Gullas, Paulino (1935). «Why we compromised», Philippines Free Press. 9 de febrero, pp. 41-42.

«La función del Círculo...» (1935). La Vanguardia. 13 de febrero, p. 5.

«Los embajadores hispanos» (1935). Philippines Free Press. 12 de enero, p. 56.

«iLos embajadores se van!» (1935). Philippine Free Press, 26 enero, p. 53.

«Luna y Resurrección Hidalgo...» (1935). La Opinión. 11 de enero, p. 4.

«Only merit counts» (1935). Philippine Free Press. 2 de febrero, p. 42.

«Palacios y Diego comentan sobre el teatro filipino» (1935). Philippines Free Press. 23 de febrero, p. 53.

«Para dar mayor impulso...» (1935). Philippines Free Press. 16 de febrero, p. 56.

«Recto entertains for Spanish Savants» (1935). The Tribune. 20 de enero, p. 32.

«Spain's Cultural Envoys» (1935). Philippines Free Press. 2 de febrero, pp. 41-42. «Spanish Educators...» (1935). The Tribune. 5 de enero, p. 3.

\section{BIBLIOGRAFÍA CITADA}

Agoncillo, Teodoro (2006). History of the Filipino People. Quezon City: Garotech Publishing. 
Alonso, Dámaso (1988). Poetas españoles contemporáneos. Madrid: Gredos.

Álvarez Tardío, Beatriz (2012). «El problemático lugar de José Rizal dentro de la literatura española», en M. ${ }^{a}$ Dolores Elizalde Pérez-Grueso (ed.), Entre España y Filipinas: José Rizal, escritor. Madrid: Biblioteca Nacional, pp. 127-148.

Arguilla, Manuel Estadillo, Estaban Nedruda y Teodoro Agoncillo (eds.) (1940). Literature under the Commonwealth. Manila: Philippine Writers' League.

Casanova, Pascale (2001). La república mundial de las Letras. Barcelona: Anagrama.

Delgado López-Escalonilla, Lorenzo (1994). «Las relaciones culturales de España en tiempo de crisis: de la II República a la Guerra Mundial», Espacio, tiempo y forma. Serie V, Historia Contemporánea. 7, pp. 259-294.

Díaz-Trechuelo, M. ${ }^{a}$ Lourdes (2000). «Filipinas y el 98», en Francisco Morales (coord.), III Coloquio de historia canario-americana: VIII Congreso Internacional de Historia de América (AEA) 1998. Las Palmas: Cabildo de Gran Canaria y Casa de Colón, pp. 664681

Diego, Elena (1996). «Diario de a bordo de un viaje a Filipinas», Ínsula. 597-598, p. 32.

Diego, Gerardo (1946). «Estampas filipinas», Revista de Indias. VII, 25, pp. 587-599.

Diego, Gerardo (1997). Obras completas, IV, ed. Francisco Javier Díez de Revenga. Madrid: Alfaguara.

Diego, Gerardo (2007). Diario de a bordo, ed. Jacques Issorel y Anne Lacroix. Málaga: Centro Cultural Generación del 27-Fundación Gerardo Diego.

Diego, Gerardo (2008). "Autobiografía», ed. Marino Gómez Santos, Cuaderno Adrede 5. Santander: Fundación Gerardo Diego, disponible en: $<$ http://www.fundaciongerardodiego. com/gerar/autobiografia/> [ref. de: 22/08/2015].

Gallego Morell, Antonio (1956). Vida y poesía de Gerardo Diego. Barcelona: Editorial Aedos.

Gimeno Perelló (2011). «Esbozo de una utopía: las Misiones Pedagógicas de la II República española (1931-1939)», Faro. 13, disponible en: <http://web.upla.cl/revistafaro/n13/ art15.htm> [ref. de: 22/08/2015].

Jolipa, Nora T. (1996). «Lost Paradise. American Colonialism and the Filipino Writer in Spanish», en Elmer A. Ordóñez (ed.), Nationalist Literature: A Centennial Forum. Quezon City: University of the Philippines Press, pp. 24-32.

Kramer, Paul A. (2006). The Blood of Government. Race, Empire, the United States and the Philippines. Manila: Ateneo de Manila University Press.

Lumbera, Bienvenido (2002). «From Colonizer to Liberator: How U.S. Colonialism Succeeded in Reinventing Itself After the Pacific War», en Angel Velasco Shaw (ed.), Vestiges of the War. The Philippine-American War and the Aftermath of an Imperial Dream. 1899-1999. Nueva York: Nueva York University Press, pp. 193-203.

Luque Talaván, Miguel (2013). «Como meteoros incandescentes: mensajeros de ciencia y de letras españoles en la Filipinas de principios del siglo XX», Perro berde: revista cultural hispanofilipina. 5, pp. 78-84.

Matibag, Eugenio (2013). «Staging the Nation: Claro M. Recto's Domestic Dramas», World Languages and Cultures Publications. 53, pp. 172-203, disponible en: <http://lib.dr. iastate.edu/language_pubs/53> [ref. de: 31/7/17].

Mojares, Resil (1998). Origins and Rise of the Filipino Novel. Quezon City: University of the Philippines Diliman Press.

Morris, Nancy (1995). Puerto Rico: Culture, Politics and Identity. Westport, Connecticut: Praeger-Greenwood.

Neila, José Luis (2002). España república mediterránea. Seguridad colectiva y defensa nacional: 1931-1936 (1885-1888). Tesis doctoral, Universidad Complutense de Madrid, 
Departamento de Historia Contemporánea. Disponible en: <http://eprints.ucm.es/2399/1/ AH0017001.pdf> [ref. de: 21/08/2015].

Ortuño Casanova, Rocío (2014). «La representación de España en la poesía fillipina en castellano de la época de ocupación americana: idealización, exotización y diferenciación», Transmodernity. 4 (1), pp. 154-167 (disponible en <https://escholarship.org/uc/ item/7pd0p015> [ref. de: 22/08/2015]

Ortuño Casanova, Rocío (2015). «Manila existe: Filipinas y la recuperación de la memoria histórica en la novela española», Neophilologus. 99, 3, pp. 433-448. https://doi. org/10.1007/s11061-014-9425-1

Palacios, Julio (1935). Filipinas, orgullo de España. Un viaje por las islas de la Malasia. Madrid: C. Bermejo, impresor.

Peña, Wystan de la (2000) «The Spanish-English Language "War"», Linguae et Litterae. IV-V, pp. 6-28.

Rodao, Florentino (2012). «El español durante la guerra civil: las revistas ideologizadas», en Isaac Donoso (ed.), Historia cultural de la lengua española en Filipinas: ayer y hoy. Madrid: Verbum, pp. 459-509.

Rodao, Florentino (2014). La comunidad Española en Filipinas. 1935-1939. El impacto de la Guerra Civil española y de los comienzos de los preparativos de la independencia de Filipinas en la evolución de su identidad. Tesis doctoral, Universidad de Tokio-El Taller Digital, disponible en: <http://eprints.ucm.es/23171/9/totalpdf12-S.pdf> [ref. de: 21/08/2015].

Sánchez Gómez, Luis Ángel (2002). «Las exhibiciones etnológicas y coloniales decimonónicas y la Exposición de Filipinas de 1887», Revista de Dialectología y Tradiciones Populares. LVII, 2, pp. 79-104. https://doi.org/10.3989/rdtp.2002.v57.i2.174

Trota José, Ricardo (1990). «The Tribune during the Japanese Occupation», Philippine Studies. 38, pp. 45-64.

Fecha de recepción: 23 de septiembre de 2015.

Fecha de aceptación: 26 de mayo de 2016. 